\title{
Characterization of Ni-Co-PVC and Ni-Cu-PVC Alloys Prepared By Mechanical Alloying Technique (MAT)
}

\author{
Riyanto and Mohamed Rozali Othman
}

\author{
Electrosynthesis Laboratory (Room B105), School of Chemical Sciences and Food Technology, Faculty of Science and \\ Technology, University Kebangsaan Malaysia, 43600 UKM, Bangi, Selangor Darul Ehsan, Malaysia
}

\begin{abstract}
A study was carried out to characterize Ni-Co-PVC and Ni-Cu-PVC composite materials prepared by mechanical alloying technique (MAT) using SEM, EDS and electrochemical test. Composite materials were prepared by mixing together $95 \%$ of metal powder $(\mathrm{Ni}+\mathrm{Co}$ or $\mathrm{Ni}+\mathrm{Cu})$ with $5 \%$ PVC. PVC was used as a binder and tetrahydrofuran (THF) was used as a solvent in composite material preparation. Based on the SEM and EDS studies on those composite materials, both Ni-Co-PVC and Ni-Cu-PVC composite materials were found to be homogeneous and composed of aggregation of nickel and Co particles separated by gaps of PVC. The electrochemical test found that the response is very good in $\mathrm{KOH}$ and ethanol solution. Based on the $\mathrm{CV}$, Ni-Co-PVC and $\mathrm{Ni}-\mathrm{Cu}-\mathrm{PVC}$ composite materials showed a synergistic effect as the electrocatalyst. Applications of these materials are as an electrode for electrocatalyst in fuel cell and for electrosynthesis of organic compounds.
\end{abstract}

Keywords: Ni-Co-PVC, Ni-Cu-PVC, MAT.

\section{INTRODUCTION}

Electrocatalytic activity of copper and nickel materials was strongly dependent on their morphology, composition, surface area and structure, which in turn depends on the preparation methods [1]. One of the techniques of making the porous electrode is by incorporating polymer material like polyvinyl chloride (PVC) with the powder of respected metals [2-6]. As being the transition elements, with their electronic layer $d$ incomplete, these metals have shown good electrocatalytic properties for the oxygen reduction reaction (ORR) and electrooxidation of organic compounds in alkaline solution. Recently, there has been a proposal of copper combined with $\mathrm{Pd}, \mathrm{Ag}, \mathrm{Ni}$ or $\mathrm{Au}$ for the ORR [7].

Mechanical Alloying Technique (MAT) is an alternative process used to prepare electrocatalysts. MAT is an intensive energy process of mechanical grinding for the preparation of alloyed powders or composites in powder form. The MAT to prepare cobalt-nickel alloys and to evaluate their performance for the oxygen reduction reaction in alkaline media has been carried out [7]. The higher current density associated to the cobalt-nickel an alloy was attributed to a synergistic effect for the electrocatalytic activity [7]. The existence of the two metals will cause synergistic effect [3,8-10], bifunctional oxygen electrode [11], and active bifunctional catalyst in alkaline solution and improvement in acetic acid formation [12-14]. The addition of certain percentage of Co powder into nickel composite electrode will enhance the electrode reactivity [13-15], increase the oxygen evolution reaction (OER) and will be economically feasible for the commercial use [15].

\footnotetext{
*Address correspondence to this author at the Electrosynthesis Laboratory (Room B105), School of Chemical Sciences and Food Technology, Faculty of Science and Technology, University Kebangsaan Malaysia, 43600 UKM, Bangi, Selangor Darul Ehsan, Malaysia;

Tel: +603-89215424; Fax: +603-89215410;

E-mail:rozali@pkrisc.cc.ukm.my or mohamed_rozali@yahoo.com
}

Powders of nickel and copper metal are widely used in numerous applications because they possess good catalytic, electronic and magnetic properties [8]. Ni powder, for example, has been used in catalysis for the direct cracking of methane whereas $\mathrm{CeO}_{2}$-supported copper catalysts have been tested for $\mathrm{CO}$ reduction. The influences of aggregation on the magnetic properties of $\mathrm{Ni}$ nanoparticles synthesized by hydrogen reduction and the magneto-resistance of Ni-based thick films have also been investigated. Nickel and copper powders are extensively used as the active anode material in solid oxide fuel cells. When a metal is associated with another metal in bimetallic or alloy form, the properties of the resulting material can be enhanced with respect to those of the pure metals. This is the case for Ni-based bimetallic particles containing copper, which exhibit better catalytic activity $[16,17]$ and selectivity $[18,19]$ than monometallic nickel [8]. To improve the properties of pure $\mathrm{Ni}$ and $\mathrm{Cu}$ powders, several methods have been proposed for the preparation of bimetallic and alloyed $\mathrm{Ni}-\mathrm{Cu}$ particles. Reduction of a mixture of nickel and copper compounds under hydrogen has been used to prepare $\mathrm{Ni}-\mathrm{Cu}-\mathrm{Al}$ and $\mathrm{Ni}-\mathrm{Cu} / \mathrm{Al}_{2} \mathrm{O}_{3}$ catalysts, and $\mathrm{Ni}-\mathrm{Cu}$ alloys. Evaporation of a $\mathrm{Ni}-\mathrm{Cu}$ alloy and cocondensation with organic solvents gives bimetallic $\mathrm{Ni}-\mathrm{Cu}$ colloids [20].

Compared with nickel, copper shows lower overvoltage and higher enthalpy of $\mathrm{OH}^{-}$absorption for the OER [16]. Thus, pure copper can be a good electrocatalyst for the OER. It indicates that the addition of copper with cobalt and nickel would increase the electrocatalytic activity for OER. Although, the oxygen evolution study has been carried out recently using $\mathrm{Co}-\mathrm{Cu}$ alloy and $\mathrm{Ni}-\mathrm{Cu}$ alloy, the same by using the prepared $\mathrm{Ni}-\mathrm{Cu}-\mathrm{PVC}$ with mechanical alloy is unknown. Because of the high availability and low cost of copper, the $\mathrm{Cu}$-based anodes will be highly encouraging [21].

In this study, we are concerned with the characterization of Ni-Co-PVC and Ni-Cu-PVC composite material prepared 
by mechanical alloying. These techniques are very simple, using low temperature process, low cost design and the properties of the metal will not change. Scanning electron microscopy (SEM) images show the porous microstructure of the composite material on material surface. Energy dispersive spectroscopy (EDS) or energy dispersive analysis of $\mathrm{X}$-ray (EDX) analysis showed the composition and distribution of $\mathrm{Ni}$ and $\mathrm{Co}$ on material surface. The electrochemical properties of the composite material were studied by cyclic voltammetry $(\mathrm{CV})$ method in $\mathrm{KOH}$ and ethanol solutions.

\section{MATERIALS AND METHODOLOGY}

\subsection{Materials}

All solutions were prepared by dissolving their analytical grade reagent (Merck) in deionised distilled water. $\mathrm{KOH}$ was used as the supporting electrolyte. Nitrogen was used to deaerate the solutions and to keep an inert atmosphere over the reaction solution during the oxidation process. Ethanol solutions were prepared by dilution of absolute ethanol (BDH laboratory supplies) with deionised distilled water.

\subsection{Methodology}

\section{Synthesis}

$\mathrm{Ni}-\mathrm{Co}-\mathrm{PVC}$ and Ni-Cu-PVC materials were prepared by mixing same weighed portion of $\mathrm{Cu}$ powder or $\mathrm{Co}$ powder $(<$ 2 micron in size and $99.9 \%$ purity, Systerm), Ni powder $(<2$ micron in size and $99.9 \%$ purity, Aldrich Chemical Company) and PVC in $4 \mathrm{~mL}$ tetrahydrofuran (THF) solvent and swirled flatly to homogeneous followed by drying in an oven at $100{ }^{\circ} \mathrm{C}$ for 3 hours. The mixture was placed in $1 \mathrm{~cm}$ diameter stainless steel mould and pressed at $10 \mathrm{ton} / \mathrm{cm}^{2}$. A typical pellet contained approximately same amount of $\mathrm{Ni}$ :Co powder and $\mathrm{Ni}-\mathrm{Cu}$ powder, and approximately $5 \%$ of PVC polymer. The total weighed of the pellet obtained is approximately $1.5 \mathrm{~g}$.

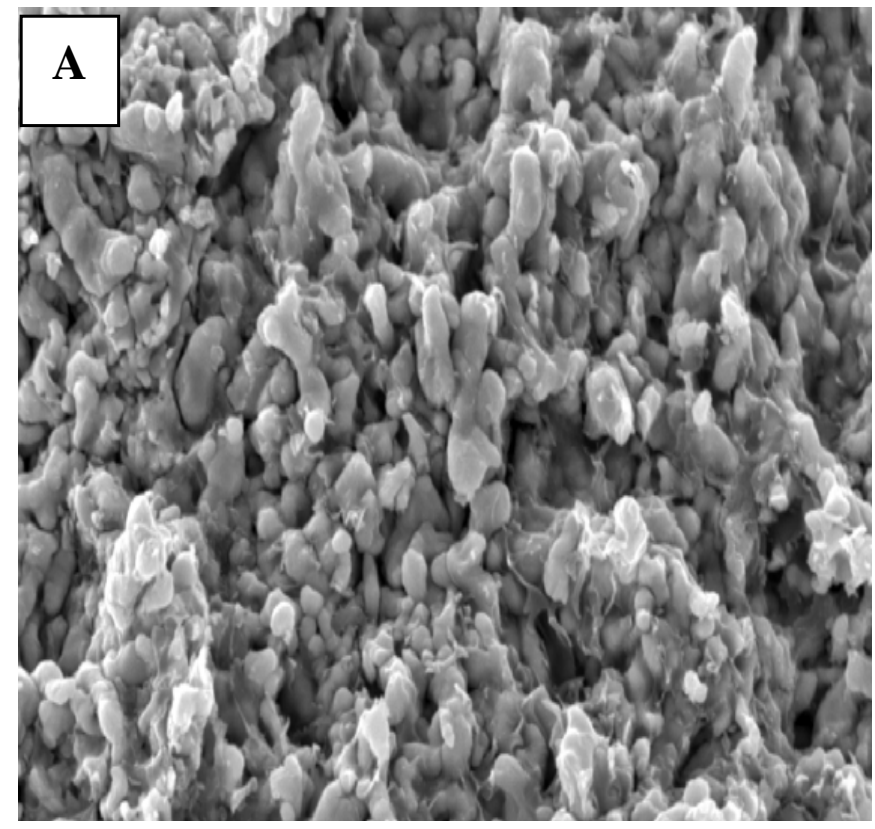

\section{Characterization}

The surface characterizations of the material using SEM and EDS or EDX were performed on the JSM 5400 microscope equipped with a microprobe Voyager Noran System. $\mathrm{Au}$ metal was used for sputtering process.

\section{Electrochemical Tests}

Universal Pulsa Dynamic EIS, Voltammetry, Voltalab potentiostat (Model PGZ 402) was used for electrochemical behavior measurement; data acquisition was accomplished using the Voltamaster 4 software. Cyclic voltammetry experiments were performed in a three electrodes system using $\mathrm{Ni}-\mathrm{Co}-\mathrm{PVC}$ and $\mathrm{Ni}-\mathrm{Cu}-\mathrm{PVC}$ pellets as a working electrode (anode), saturated calomel electrode (SCE) as reference electrode and platinum wire as the counter electrode. All potentials given are with respect to the SCE reference electrode.

\section{RESULT AND DISSCUSION}

\subsection{Characterization of Ni-Co-PVC and Ni-Cu-PVC Ma- terials}

Fig. (1A) shows the SEM micrograph obtained from the morphological study of freshly prepared $\mathrm{Ni}_{47.5} \mathrm{Co}_{47.5}-\mathrm{PVC}_{5}$ electrode, while Fig. (1B) shows the EDS spectrum for the same electrode. The SEM micrograph obtained shows that the electrode surface was very rough, irregular and having porous characteristic (Fig. 1A). It has been reported that electrode prepared using metal-PVC powder produced an electrode with a very rough surface, irregular and formed a lamellar orientated particles [4-6]. Fig. (1A) indicates that the surface morphology is highly homogeneous and composed of aggregates of nickel and Co particles separated by gaps of PVC which voids between aggregate of nickel and cobalt. These morphological, structure and porosity characteristics enable the use of this Ni-Co-PVC composite electrode as current collector for different catalysts with good adherence [4,5]. Fig. (2A) shows the SEM micrograph ob-

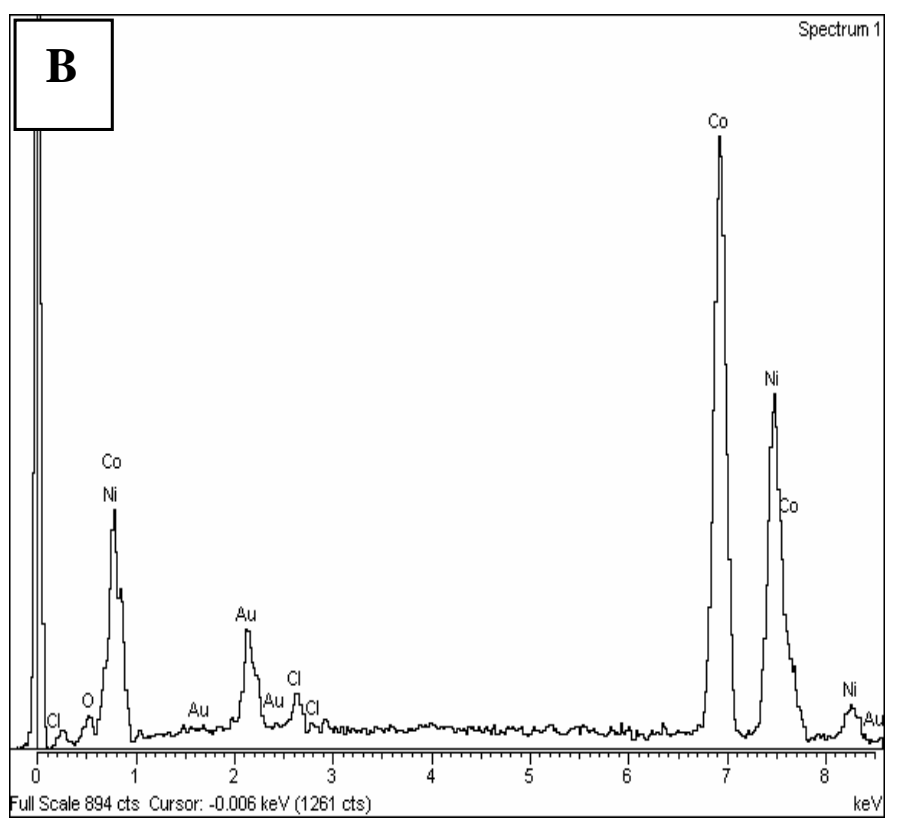

Fig. (1). Physical characterization of $\mathrm{Ni}_{47.5} \mathrm{Co}_{47.5}-\mathrm{PVC}_{5}$ materials (A) scanning electron microscopic images (magnification $\left.\mathrm{x} 4000\right)$ at cross section and (B) EDS spectra composition analysis. 

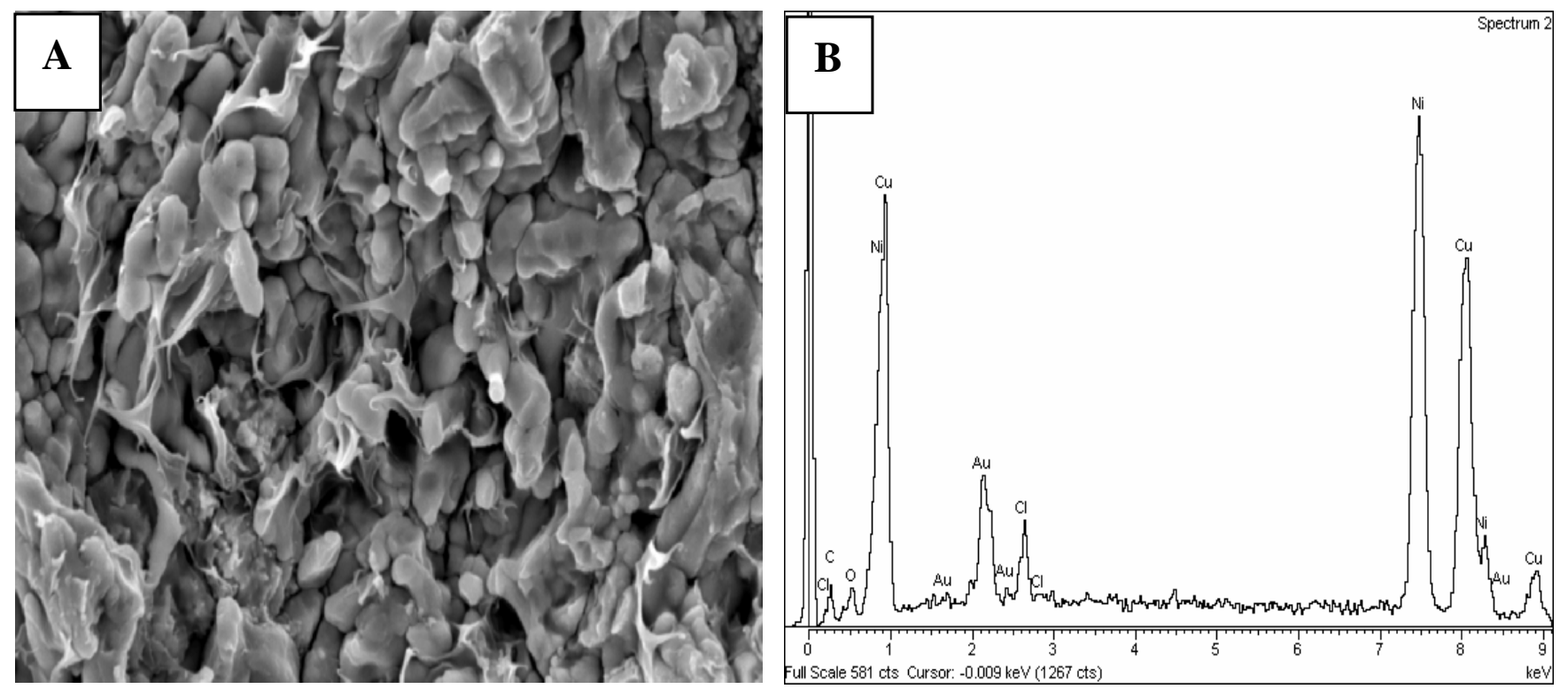

Fig. (2). Physical characterization of $\mathrm{Ni}_{47.5} \mathrm{Cu}_{47.5}-\mathrm{PVC}_{5}$ materials (A) scanning electron microscopic images (magnification $\left.\mathrm{x} 4000\right)$ at cross section and (B) EDS spectra composition analysis.

tained from the morphological study of freshly prepared Ni${ }_{47.5} \mathrm{Cu}_{47.5}-\mathrm{PVC}_{5}$ electrode, while Fig. (2B) shows the EDS spectrum for the same electrode.

\subsection{Electrochemical Characterization}

Fig. (3A) shows the cyclic voltammogram of $\mathrm{Ni}_{95.0}-\mathrm{PVC}_{5}$ (Ni-PVC) electrode. The oxidation peaks for the oxidation of $\mathrm{Ni}$ (II) to $\mathrm{Ni}$ (III) $\left\{\mathrm{Ni}(\mathrm{OH})_{2}\right.$ to $\left.\mathrm{NiOOH}\right\}$ are represented by A1 peak (anodic peak) in Fig. (3A). Oxidation of $\mathrm{Ni}(0)$ or $\mathrm{Ni}$ metal to $\mathrm{Ni}$ (II) in the form of $\alpha \mathrm{Ni}(\mathrm{OH})_{2}$ has always occurred in the negative potential $(-0.8 \mathrm{~V}$ up to $-1.5 \mathrm{~V}$ ) (not shown in this cyclic voltammogram) as already suggested by many researches $[3,22,23]$. While at the potential of $-0.8 \mathrm{~V}$ up to $+0.3 \mathrm{~V}$, represents the changing process of $\alpha \mathrm{Ni}(\mathrm{OH})_{2}$ to $\beta \mathrm{Ni}(\mathrm{OH})_{2}$, where $\alpha \mathrm{Ni}(\mathrm{OH})_{2}$ was easily change to $\beta \mathrm{Ni}(\mathrm{OH})_{2}$. A1 peak represents the oxidation process of $\beta \mathrm{Ni}(\mathrm{OH})_{2}$ to $\mathrm{NiOOH}[10,24-28]$.

$\mathrm{C} 1$ (cathodic peak) in Fig. (3A) represents two forms of crystallographic from oxyhydroxide $\alpha$ and $\beta$ [22]. Nickel oxyhydroxide $(\mathrm{NiOOH})$ is capable to oxidize a number of functional groups, for example primary alcohols may be oxidized to carboxylic acids. Nickel has been reported to be a good electrode for the oxidation of various organic compounds [22]. A redox couple of nickel, i.e., nickel hydroxide $\left\{\mathrm{Ni}(\mathrm{OH})_{2}\right\}$ and nickel oxyhydroxide $(\mathrm{NiOOH})$ was shown to be involved in the oxidation of alcohol at nickel electrode in alkaline media. Fig. (3B) shows the cyclic voltammogram of Co-PVC in $1.0 \mathrm{M} \mathrm{KOH}$. A1 peak represents oxidation of Co (I) to Co (II) and A2 peaks represents oxidation of Co (II) to Co (III) [29]. $\mathrm{C} 1$ and $\mathrm{C} 2$ peaks represent reduction of $\mathrm{Co}$ (III) to Co (II) and Co (II) to Co (I), respectively.

Figs. (3C) and (3D) show a cyclic voltammogram of NiCo-PVC electrode in $1.0 \mathrm{M} \mathrm{KOH}$ where both $\mathrm{A} 1$ and $\mathrm{A} 2$ peaks in Figs. (3C) and (3D) represent the anodic peaks. A1 peaks represent oxidation of Co (II) to Co (III) and A2 peak represents oxidation of $\mathrm{Ni}$ (II) to $\mathrm{Ni}$ (III). $\mathrm{C} 1$ and $\mathrm{C} 2$ peaks in Figs. (3C) and (3D) represent reduction Ni (III) to Ni (II) and Co (III) to Co (II). From Figs. (3C) and (3D), redox couple occurred was A1/C2 and A2/C1. Fig. (3D) supporting the occurrences of redox couple, the higher the composition of $\mathrm{Ni}$ powder (up to $76 \%$ ), the higher the electrochemical activity for redoxs couple $\mathrm{A} 2 / \mathrm{C} 1$ or $\mathrm{Ni}(\mathrm{III}) / \mathrm{Ni}(\mathrm{II})$, while the lower the current density for $\mathrm{A} 1 / \mathrm{C} 2$ or $\mathrm{Co}$ (III) to Co (II) redox couple. Redox couple is a very important parameter for the electrocatalysis in the electrosynthesis of organic material. According to Kim and Park [30], reaction mechanism of electrocatalyst activity on the surface of $\mathrm{Ni}$ electrode is as follows:

$\mathrm{OH}^{-}+\mathrm{Ni}(\mathrm{OH})_{2} \rightleftharpoons \mathrm{NiOOH}+\mathrm{H}_{2} \mathrm{O}+\mathrm{e}^{-}$

$\mathrm{NiOOH}+\mathrm{CH}_{3} \mathrm{CH}_{2} \mathrm{OH} \longrightarrow$ Intermediate $1+\mathrm{Ni}(\mathrm{OH})_{2}$

$\mathrm{NiOOH}+$ Intermediate $1 \longrightarrow \mathrm{CH}_{3} \mathrm{CHO}+\mathrm{Ni}(\mathrm{OH})_{2}$

$\mathrm{NiOOH}+\mathrm{CH}_{3} \mathrm{CHO} \longrightarrow$ Intermediate $2+\mathrm{Ni}(\mathrm{OH})_{2}$

$\mathrm{NiOOH}+$ Intermediate $2 \longrightarrow \mathrm{CH}_{3} \mathrm{COOH}+\mathrm{Ni}(\mathrm{OH})_{2}$

and on the surface of Co electrode is as follows:

$\mathrm{Co}(\mathrm{OH})_{2}+\mathrm{OH}^{-} \rightleftharpoons \mathrm{CoOOH}+\mathrm{H}_{2} \mathrm{O}+\mathrm{e}^{-}$

$\mathrm{CoOOH}+\mathrm{CH}_{3} \mathrm{CH}_{2} \mathrm{OH} \longrightarrow$ Intermediate $1+\mathrm{Co}(\mathrm{OH})_{2}$

$\mathrm{CoOOH}+$ Intermediate $1 \longrightarrow \mathrm{CH}_{3} \mathrm{CHO}+\mathrm{Co}(\mathrm{OH})_{2}$

$\mathrm{CoOOH}+\mathrm{CH}_{3} \mathrm{CHO} \longrightarrow$ Intermediate $2+\mathrm{Co}(\mathrm{OH})_{2}$

$\mathrm{CoOOH}+$ Intermediate $2 \longrightarrow \mathrm{CH}_{3} \mathrm{COOH}+\mathrm{Co}(\mathrm{OH})_{2}$

Reaction mechanisms $1-5$ occurred for the $\mathrm{Ni}(\mathrm{OH})_{2} / \mathrm{NiOOH}$ redox couple, while reaction mechanism 610 occurred for the $\mathrm{Co}(\mathrm{OH})_{2} / \mathrm{CoOOH}$ couple redox.

Fig. (4A) shows the cyclic voltammogram (CV) of $\mathrm{Cu}_{95.0}-\mathrm{PVC}_{5}(\mathrm{Cu}-\mathrm{PVC})$ in $1.0 \mathrm{M} \mathrm{KOH}$ with the sweep potential from potential -700 up to $+700 \mathrm{mV}$, and then return from $+700 \mathrm{mV}$ up to $-700 \mathrm{mV}$. The A1, A2, A3, and A4 peaks represent the anodic peaks. These peaks are related to the 


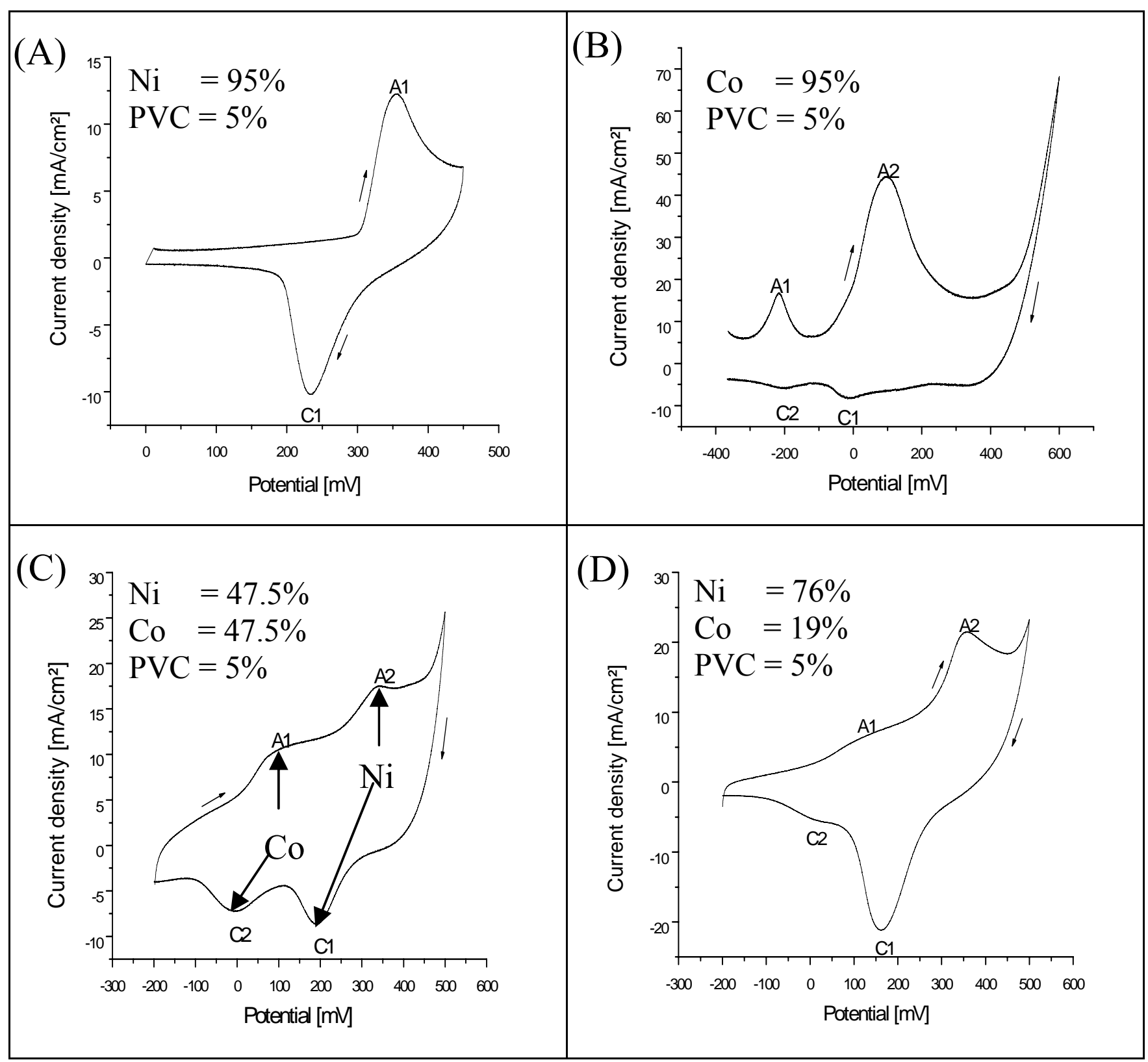

Fig. (3). Cyclic voltammograms in $1.0 \mathrm{M} \mathrm{KOH}$, scan rate $10 \mathrm{mV} / \mathrm{sec}$.

oxidation of $\mathrm{Cu}$ to $\mathrm{Cu}$ (I), $\mathrm{Cu}$ (II) and $\mathrm{Cu}$ (III) $[2,31,32]$. A1 peak represents the oxidation of $\mathrm{Cu}(0)$ to $\mathrm{Cu}$ (I) $\{\mathrm{Cu}$ metal to $\mathrm{CuOH}$ or $\left.\mathrm{Cu}_{2} \mathrm{O}\right\}$ [31,32], while $\mathrm{A} 2$ peak represents solubilization of species process [32]. The reaction mechanism of solubilization of species process is as follows [32]:

$\mathrm{Cu}^{0}+3 \mathrm{OH}^{-} \longrightarrow \mathrm{HCuO}_{2}^{-}+\mathrm{H}_{2} \mathrm{O}+2 \mathrm{e}^{-}$

$\mathrm{Cu}(\mathrm{OH})_{2}+2 \mathrm{OH}^{-} \rightleftharpoons \mathrm{CuO}_{2}{ }^{2-}+2 \mathrm{H}_{2} \mathrm{O}$

A3 peak represents the oxidation of $\mathrm{Cu}$ (I) to $\mathrm{Cu}$ (II) and A4 peaks represent the oxidation of $\mathrm{Cu}$ (II) to $\mathrm{Cu}$ (III) $\left\{\mathrm{Cu}(\mathrm{OH})_{2}\right.$ to $\left.\mathrm{CuOOH}\right\}$ [32].

Fig. (4B) shows the $\mathrm{CV}$ of $\mathrm{Ni}_{47.5} \mathrm{Cu}_{47.5}-\mathrm{PVC}_{5}$ electrode in $1.0 \mathrm{M} \mathrm{KOH}$ indicating that $\mathrm{A} 1, \mathrm{~A} 2, \mathrm{~A} 3$ and $\mathrm{A} 4$ peaks represent the oxidation of $\mathrm{Cu}$, while $\mathrm{A} 3$ peak represents the overlapping oxidation of $\mathrm{Cu}$ (I) to $\mathrm{Cu}$ (II) and $\mathrm{Ni}$ (II) to $\mathrm{Ni}$ (III). Mixing of $\mathrm{Ni}$ and $\mathrm{Cu}$ with the same compositions causing both metals has the same opportunity as electrocatalyst, however the overlapping of the A3 peak will occur. From Fig. (4B), the redox couple occurred was $\mathrm{A} 3 / \mathrm{C} 1$ and $\mathrm{A} 4 / \mathrm{C} 2$ or $\mathrm{Ni}(\mathrm{III})$ to $\mathrm{Ni}$ (II) and $\mathrm{Cu}$ (III) to $\mathrm{Cu}$ (II).

\subsection{Electrochemical Responds on Ethanol}

Fig. (5) shows the cyclic voltammograms of $0.25 \mathrm{M}$ ethanol in $1.0 \mathrm{M} \mathrm{KOH}$ using Ni-PVC electrode. With ethanol in the reaction mixture (curve a), at $300 \mathrm{mV}$ and below, the oxidation of ethanol is sustained by the involvement of adsorbed hydroxyl group (from $\mathrm{KOH}$ ) on the electrode surface, while at higher potentials region $(300 \mathrm{mV}$ to $500 \mathrm{mV})$ the electrooxidation process is attributed to the formation of $\mathrm{NiOOH}$ species. However, without ethanol (curve b), the adsorption of hydroxyl group (from $\mathrm{KOH}$ ) and the formation of $\mathrm{NiOOH}$ on the electrode surface occurred at higher potential (Fig. 5b). Adsorption of ethanol on the electrode surface 


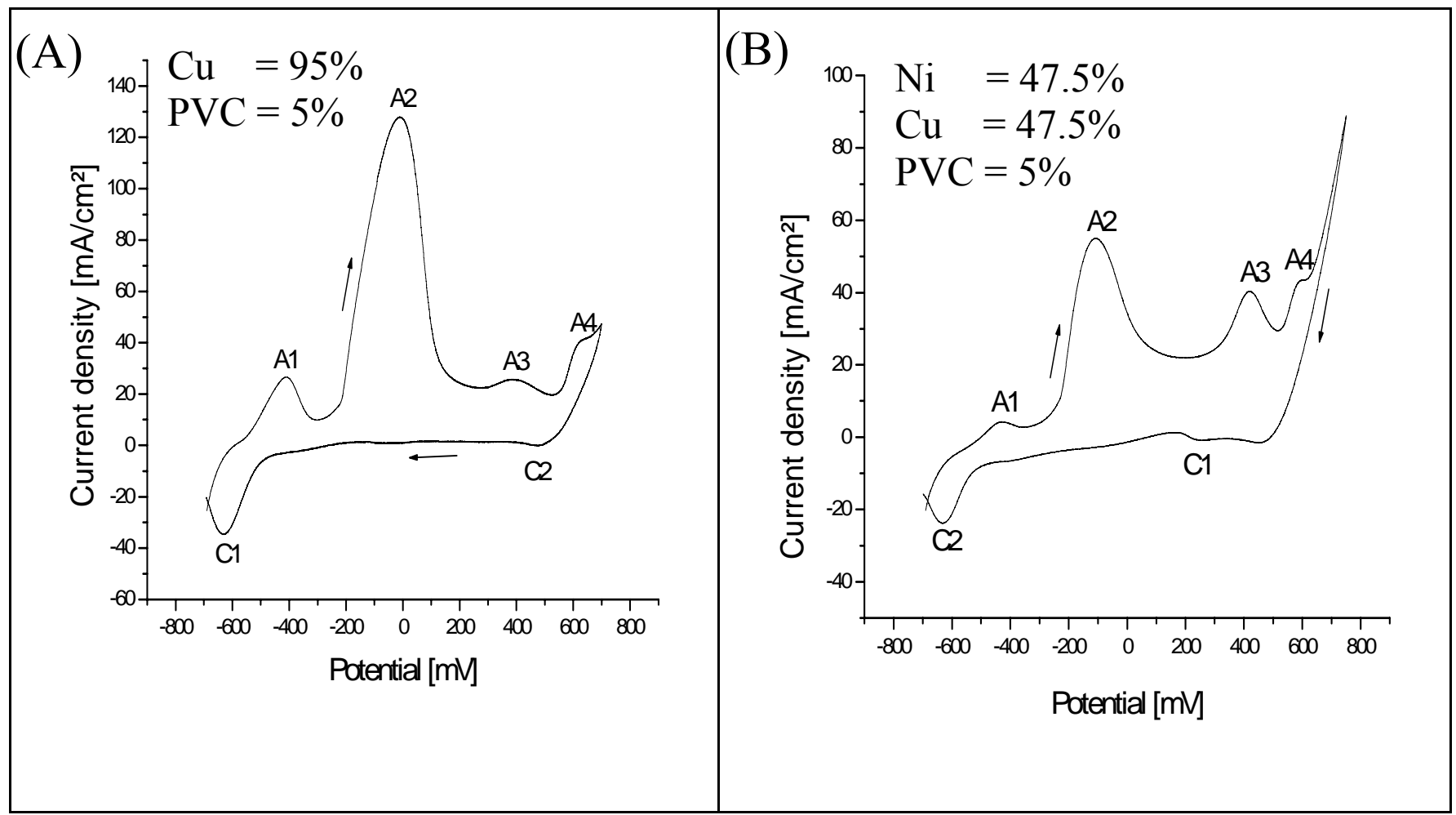

Fig. (4). Cyclic voltammograms in $1.0 \mathrm{M} \mathrm{KOH}$, scan rate $10 \mathrm{mV} / \mathrm{sec}$.

(A2 peak) will immediately occur after the completion of $\mathrm{NiOOH}$ formation.

Fig. (6a) shows a cyclic voltammogram in $1 \mathrm{M} \mathrm{KOH}$ using $\mathrm{Ni}_{47.5} \mathrm{Co}_{47.5}-\mathrm{PVC}_{5}$ electrode, while Fig. (5b) shows the cyclic voltammogram of $0.25 \mathrm{M}$ ethanol in $\mathrm{KOH}$ for the same electrode. Peaks A1 and A2 in Fig. (6b) represent the oxidation peaks of $\mathrm{Co}\{\mathrm{Co}$ (I) to $\mathrm{Co}$ (II) and $\mathrm{Co}$ (II) to $\mathrm{Co}$ (III) $\}$ and A3 peak represents the oxidation peak of ethanol. Electrooxidation of ethanol in alkaline solution may produce acetic acid as yield [33]. Oxidation peaks of $\mathrm{Ni}$ (II) to $\mathrm{Ni}$ (III) overlap with the oxidation peak of ethanol which was presented by $\mathrm{A} 3$ peak. Based on the $\mathrm{CV}$ in Figs. (5) and (6), the $\mathrm{Ni}_{47.5} \mathrm{Co}_{47.5}-\mathrm{PVC}_{5}$ electrode has shown good activity on electrooxidation of ethanol in alkaline solution compared to $\mathrm{Ni}$-PVC electrode. Oxidation peaks of ethanol using Ni-PVC electrode (A2 peak in Fig. (5)) and $\mathrm{Ni}_{47.5} \mathrm{Co}_{47.5}-\mathrm{PVC}_{5}$ electrode (A3 peak in Fig. (6)) showed the current density for both electrodes approximately are $62 \mathrm{mAcm}^{-2}$ and $90 \mathrm{mAcm}^{-}$ ${ }^{2}$, respectively. The higher current density showed higher electrochemical activity [7].

The $\mathrm{C} 1$ peak in Fig. (6a) is a reduction peak for Ni (III) in the form of $\mathrm{NiOOH}$ to $\mathrm{Ni}$ (II) which is in the form of $\mathrm{Ni}(\mathrm{OH})_{2}$ [24]. This process is similar to the $\mathrm{C} 1$ peak at Fig. (3A). According to Hahn et al. [26,27] C1 peak which appears in Fig. (6a) represents the peak for the formation of $\beta$ $\mathrm{NiOOH}$, and the existence of crystallographic form of $\gamma-$ $\mathrm{NiOOH}$. The $\alpha$-form is known to be unstable in alkaline solution and slowly converted and irreversible of the $\beta$-form, while on prolonged charging; $\beta-\mathrm{NiOOH}$ converts to the $\gamma$ oxyhydroxide form [28]. C2 peak at Fig. (6a) is a reduction peak for $\mathrm{Co}$ (III) in the form of $\mathrm{CoOOH}$ to $\mathrm{Co}$ (II) which is in the form of $\mathrm{Co}(\mathrm{OH})_{2}$.

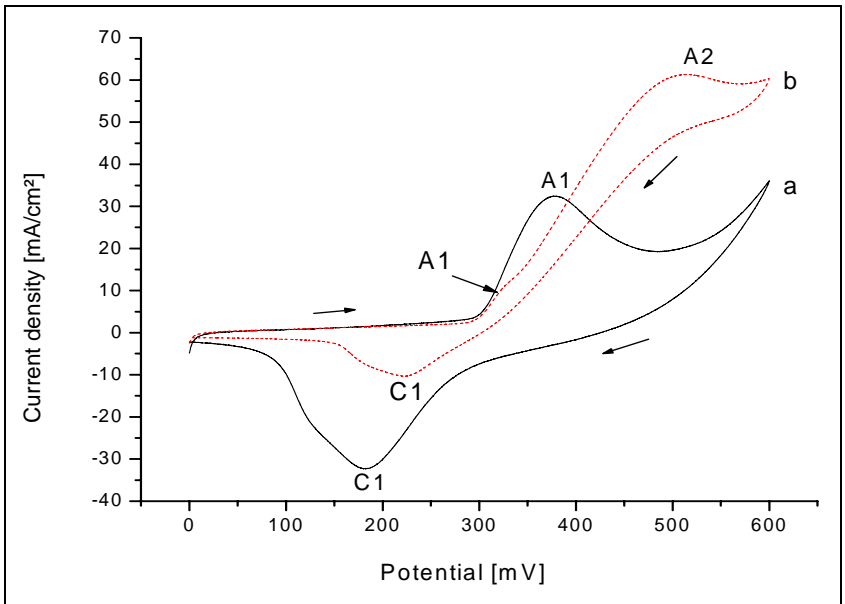

Fig. (5). Cyclic voltammograms of Ni-PVC electrode for (a) $1.0 \mathrm{M}$ $\mathrm{KOH}$ and (b) $0.25 \mathrm{M}$ ethanol in $1.0 \mathrm{M} \mathrm{KOH}$. Scan rate $10 \mathrm{mV} / \mathrm{sec}$.

Fig. (7a) shows a cyclic voltammogram of $\mathrm{Ni}_{47.5} \mathrm{Cu}_{47.5^{-}}$ $\mathrm{PVC}_{5}$ electrode in $1 \mathrm{M} \mathrm{KOH}$ while Fig. (7b) shows a cyclic voltammogram of $0.25 \mathrm{M}$ ethanol in $1 \mathrm{M} \mathrm{KOH}$ with the sweep potential is from $-700 \mathrm{mV}$ to $+750 \mathrm{mV}$ and returns to the initial potential. A1, A2 and A3 peaks in Fig. (7b) representing the anodic peaks from $\mathrm{Cu}$. A4 peak in Figs. (7a) and (7b) which has a relatively larger anodic current is related to further oxide growth as well as the change in $\mathrm{Ni}$ oxidation state from $\mathrm{Ni}$ (II) to $\mathrm{Ni}$ (III) and possibly higher if overcharging occurs [24].

A4 peak in Fig. (7a) representing the oxidation peak for $\mathrm{Cu}$ (II) to $\mathrm{Cu}$ (III), but with the existence of ethanol, overlapping with ethanol oxidation peak occurred (Fig. 7b). 


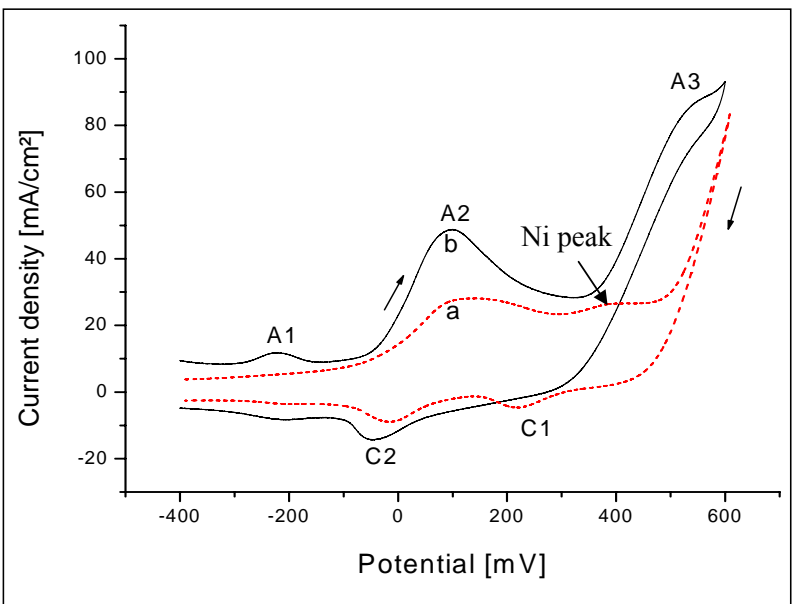

Fig. (6). Cyclic voltammograms of $\mathrm{Ni}_{47.5} \mathrm{Co}_{47.5}-\mathrm{PVC}_{5}$ electrode for (a) $1.0 \mathrm{M} \mathrm{KOH}$ and (b) $0.25 \mathrm{M}$ ethanol in $1.0 \mathrm{M} \mathrm{KOH}$. Scan rate 10 $\mathrm{mV} / \mathrm{sec}$.

From the existing of ethanol oxidation peak, it clearly showed that the oxidation of ethanol with $\mathrm{Ni}_{47.5} \mathrm{Cu}_{47.5}-\mathrm{PVC}_{5}$ electrode can be done at a potential of $600 \mathrm{mV}$, where better electrocatalytic reaction would occurr at this potential due to the formation of $\mathrm{NiOOH}$ and $\mathrm{CuOOH}$ on the surface of electrode used. At potential $600 \mathrm{mV}$ vs SCE a synergistic effect electrocatalysts would occur from the $\mathrm{NiOOH}$ and $\mathrm{CuOOH}$ species.

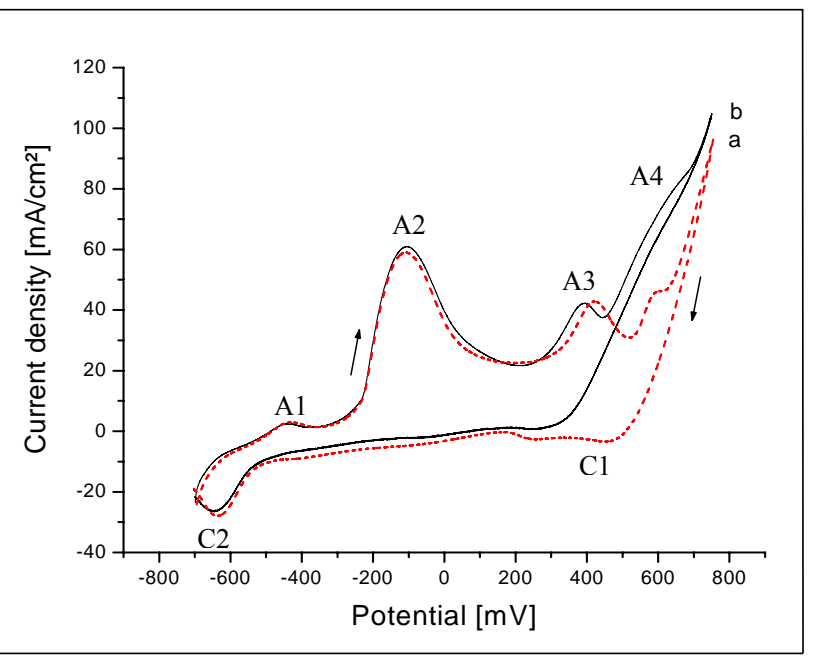

Fig. (7). Cyclic voltammograms of $\mathrm{Ni}_{47.5} \mathrm{Cu}_{47.5}-\mathrm{PVC}_{5}$ electrode for (a) $1.0 \mathrm{M} \mathrm{KOH}$ and (b) $0.25 \mathrm{M}$ ethanol in $1.0 \mathrm{M} \mathrm{KOH}$. Scan rate 10 $\mathrm{mV} / \mathrm{sec}$.

\section{CONCLUSION}

Mechanical alloying technique was found to be a good technique for the preparation of the composite material. Based on the SEM and EDS studies, both Ni-Co-PVC and $\mathrm{Ni}-\mathrm{Cu}-\mathrm{PVC}$ composite materials were found homogeneous and composed of aggregates of nickel and Co particles separated by gaps of PVC which voids between aggregate of nickel and cobalt. Based on the EDS and CV studies, both metals play the same role on the surface of material so that synergistic effect is easy to occur. The electrocatalytic ability of the composite material towards the oxidation of ethanol in $\mathrm{KOH}$ solution was tested and the results indicated that the
Ni-Co-PVC and Ni-Cu-PVC composite materials have good electrocatalytic ability.

\section{ACKNOWLEDGEMENTS}

This research was supported by the Ministry of Higher Education through the grant UKM-ST-01-FRGS0043-2006.

\section{REFERENCES}

[1] Simond O, Schaller V, Comninellis C. Theoritical model for the anodic oxidation of organics on metal oxide electrodes. Electrochim Acta 1997; 42: 2009-12.

[2] Mamuya YP, Davydenko VV, Pissis P, Lebedev EV. Electrical and thermal conductivity of polymer filled with metal powder. Eur Polym J 2002; 38: 1887-97.

[3] Jimenez MMD, Elizalde MP, Gonzalez M, Silva R. Electrochemical behaviour of nickel-polyester composite electrodes. Electrochim Acta 2000; 45: 4187-93.

[4] Davila MM, Elizalde MP, Mattusch J, Wennrich R. Study of the composite electrodes carbon-polyvinyl chloride and carbonpolyvinyl chloride/nafion by ex situ and in situ methods. Electrochim Acta 2001; 46: 3189-97.

[5] Davila M, Elizalde MP, Gonzalez M, Perez MA, Silva R. Morphological and electrochemical characterization of $\mathrm{Ni}$ polyvinychloride composites. Electrochim Acta 1998; 44: 1307-16.

[6] Gonzalez M, Elizalde MP, Banos L, Poillerat G, Davila MM. Surface characterization of $\mathrm{LaNiO}_{3} / \mathrm{Ni}-\mathrm{PVC}$ composite. Electrochim Acta 1999; 45: 741-50.

[7] Contreras MAG, Valverde SMF, Garcia JRV. Oxygen reduction reaction on cobalt-nickel alloys prepared by mechanical alloying. $\mathrm{J}$ Alloy Comp 2007; 434: 522-4.

[8] Kim MS, Rodriguez NM, Baker RTK. The interaction of hydrocarbon with copper-nickel and nickel in the formation of carbon filaments. J Catal 1991; 131: 60-73.

[9] Xu C, Shen PK, Ji X, Zeng R, Liu Y. Enhance activity for ethanol electrooxidation on Pt-MgO/C catalysts. Electrochem Commun 2005; 7: 1305-8.

[10] Yeo IH, Johnson DC. Electrochemical response of small organic molecules at nickel-copper alloy electrodes. J Electroanal Chem 2001; 495: 110-9.

[11] Rashkova V, Kitova S, Konstantinov I, Vitanov T. Vacuum evaporated thin films of mixed cobalt and nickel oxides as electrocatalyst for oxygen evolution and reduction. Electrochim Acta 2002; 47: 1555-60.

[12] Pereira MG, Jimenez MD, Elizalde MP, Robledo AM, Vante NA. Study of the electrooxidation of ethanol on hydrophobic electrodes by DEMS and HPLC. Electrochim Acta 2004; 49: 3917-25.

[13] Cox P, Pletcher D. Electrosynthesis at oxide coated electrodes: Part 1 the kinetics of ethanol oxidation at spinel electrodes in aqueous base. J Appl Electrochem 1990; 20: 549-54.

[14] Cox P, Pletcher D. Electrosynthesis at oxide coated electrodes. Part 2. The oxidation of alcohols and amines at spinel anodes in aqueous base. J Appl Electrochem 1991; 21: 11-3.

[15] Mao L, Arihara K, Sotomura T, Ohsaka T. A novel alkaline air electrode based on a combined use of cobalt hexadecafluorophthalocyanine and manganese oxide. J Electroanal Chem 2004; 49: 2515-21.

[16] Sungping W. Termination of BME-MLCC using copper-nickel bimetallic powder as electrode material. IEEE Trans Comp Pack Technol 2006; 29(4): 823-7.

[17] Park S, Vohs JM, Gorte RJ. Direct oxidation of hydrocarbons in a solid oxide fuel cell. Nature 2000; 404: 265-9.

[18] Li Y, Chen J, Chang L, Qin Y. The doping effect of copper on the catalytic growth of carbon fibers from methane over a $\mathrm{Ni} / \mathrm{Al}_{2} \mathrm{O}_{3}$ catalyst prepared from Feitknecht compound precursor. J Catal 1998; 178: 76-83.

[19] Bautista FM, Campelo JM, Garcia A, Guardeno R, Luna D, Marinas JM. Influence of Ni-Co alloying on Sepiolite-supported nickel catalysts in the liquid phase selective hydrogenation of fatty acid ethyl esters. J Mol Catal Chem 1996; 104: 229-35.

[20] Bonet F, Grugeon S, Dupont L, Urbina RH, Guery C, Tarascon JM. Synthesis and characterization of bimetallic $\mathrm{Ni}-\mathrm{Cu}$ particles. J Solid State Chem 2003; 172: 111-5. 
[21] Kibria AKM, Taradfar SA. Electrochemical studies of nickelcopper electrode for the oxygen evolution reaction (EOR). Int $\mathrm{J}$ Hydrogen Energ 2002; 27: 879-84.

[22] Azar MHP, Nerbin HR. Electrocatalytic characteristic of ascorbic acid oxidation at nickel plated aluminium electrodes modified with nickel pentacyanonitrosylferrate films. J Electroanal Chem 2000; 488: 17-24.

[23] Belgsir EM, Bouhier E, Yei HE, et al. Electrosynthesis in aqueous medium: A kinetic study of the electro catalytic oxidation of oxygenated organic molecules. Electrochim Acta 1991; 36: 115764.

[24] Medway SL, Lucas CA, Kowal A, Nichols RJ, Johnson D. In situ studies of the oxidation of nickel electrodes in alkaline solution. J Electroanal Chem 2006; 587: 172-81.

[25] Parpot P, Pires SG, Bettencourt AP. Electrocatalytic oxidation of D-galactose in alkaline medium. J Electroanal Chem 2004; 566: 401-8.

[26] Hahn F, Beden B, Croissant MJ, Lamy C. In situ UV visible reflectance spectroscopic investigation of the nickel electrodealkaline solution interface. Electrochim Acta 1986; 31: 335-42.

[27] Hahn F, Beden B, Croissant MJ, Lamy C. In situ investigation of the behaviour of a nickel electrode-alkaline solution by UV visible and IR reflectance spectroscopic. Electrochim Acta 1987; 32: 1631-6.

[28] Casella IG, Guascito MR, Sannazzaro MGJ. Voltammetric and XPS investigations of nickel hydroxide electrochemically dispersed on gold surface electrodes. Electroanal Chem 1999; 462: 202-10.

[29] Kamath PV, Ahmed MF. Cyclic voltammetric studies of nickel hydroxide and cobalt hydroxide thin films in alkali and alkaline earth metal hydroxides. J Appl Electrochem 1993; 23: 225-30.

[30] Kim JW, Park SM. Electrochemical oxidation of ethanol at thermally prepared $\mathrm{RuO}_{2}$-modified electrodes in alkaline media. J Electrochem Soc 1999; 146: 1075-80.

[31] Brisard GM, Rudnicki JD, McLarnon F, Cairns EJ. Application of probe beam deflection to study the electrooxidation of copper in alkaline media. Electrochim Acta 1995; 40: 859-65.

[32] Marioli JM, Kuwana T. Electrochemical characterization of carbohydrate oxidation at copper electrodes. Electrochim Acta 1992; 37: 1187-97.

[33] Riyanto. A Study on Electrode Designs for Electrochemical Oxidation of Ethanol to Acetic Acid in Alkaline Solution. Thesis Doctor of Philosophy. Faculty of Science and Technology, National University of Malaysia (UKM); 2008.

(C) Riyanto and Othman; Licensee Bentham Open.

This is an open access article distributed under the terms of the Creative Commons Attribution License (http://creativecommons.org/licenses/by/2.5/), which permits unrestrictive use, distribution, and reproduction in any medium, provided the original work is properly cited. 